\title{
The Relationship Between Nutritional Status Based on Subjective Global Assessment and Dialysis Adequacy
}

\author{
Effat Afaghi (iD) ${ }^{1}$, Ali Tayebi ${ }^{2}$, Seyedeh Azam Sajadi (iD ${ }^{3}$ and Abbas Ebadi (iD ${ }^{4,5,{ }^{*}}$ \\ ${ }^{1}$ Nursing Faculty, AJA University of Medical Sciences, Tehran, Iran \\ ${ }^{2}$ Nephrology and Urology Research Center, Nursing Faculty, Baqiyatallah University of Medical Sciences, Tehran, Iran \\ ${ }^{3}$ Department of Nursing Management, Nursing Faculty, AJA University of Medical Sciences, Tehran, Iran \\ ${ }^{4}$ Behavioral Sciences Research Center, Life Style Institute, Baqiyatallah University of Medical Sciences, Tehran, Iran \\ ${ }^{5}$ Nursing Faculty, Baqiyatallah University of Medical Sciences, Tehran, Iran \\ "Corresponding author: Behavioral Sciences Research Center, Life style institute, Baqiyatallah University of Medical Sciences, P.O. Box: 19575-174, Tehran, Iran. Tel: \\ +98-9122149019; Fax: +98-2182483443, Email: ebadi1347@yahoo.com
}

Received 2021 May 23; Accepted 2021 June 13.

\begin{abstract}
Background: Malnutrition is common in patients undergoing hemodialysis and leads to a decrease in dialysis adequacy. The evaluation of dialysis adequacy is very important.

Objectives: This study was done to investigate the relationship between patients' nutrition status based on Subjective Global Assessment (SGA) and their dialysis adequacy.

Methods: This cross-sectional descriptive study was conducted in Tehran, Iran, in 2019. Three hundred qualified patients were selected by cluster sampling. Before the dialysis session, measurement of height and weight and blood sampling for albumin, total iron-binding capacity (TIBC), blood urea nitrogen (BUN), and creatinine (Cr) assessment were performed. After the dialysis session, measurement of weight and second sampling for BUN were done. SGA forms were filled by patients. Patients' dialysis adequacy was calculated based on the DaugirdasII formula, and data were analyzed using SPSS 21.

Results: From 300 patients, 128 cases (42.7\%) had normal nutrition status, while 148 cases (49.3\%) had mild to moderate malnutrition and 24 cases $(8 \%)$ had severe malnutrition with mean dialysis adequacy of 1.07. The present study showed a significant statistical relationship between malnutrition and education $(\mathrm{P}<0.001)$, body mass index $(\mathrm{BMI})(\mathrm{P}=0.03)$, albumin $(\mathrm{P}<0.001), \mathrm{TIBC}(\mathrm{P}<0.001)$, and dialysis adequacy $(\mathrm{P}<0.001)$. Gender, age, and dialysis duration showed no significant relationship with nutrition status based on the SGA index.

Conclusions: The findings showed a high relative frequency of malnutrition and a decrease in patients' dialysis adequacy, which emphasize the patient's educational level, proper management of nutrition along with regular consultations by nutritionists, better implementation of the dialysis procedure, and regular follow-up of dialysis adequacy.
\end{abstract}

Keywords: Malnutrition, Subjective Global Assessment, Dialysis Adequacy, Hemodialysis

\section{Background}

Malnutrition is common in patients undergoing hemodialysis and is observed in approximately 20\% - 70\% of this group (1-4). Malnutrition is a serious predictive factor for mortality and morbidity accompanied by an increase in the rate of hospitalization, less physical activity, lower quality of life, and dialysis adequacy (5). An imbalance between energy and protein gain and food metabolism, metabolic acidosis, dietary restrictions, anorexia and poor appetite, protein and nutrient loss during dialysis, underlying diseases, such as cardiovascular problems, infection, poor nutrition management, inadequate dialysis, etc. are among influencing factors on the nutrition of hemodialysis patients (6). According to the results of a study, patients undergoing hemodialysis receive less energy and protein than the recommended amount for these patients (energy: $35 \mathrm{kcal} / \mathrm{kg}$ for patients younger than 60 years and $30 \mathrm{kcal} / \mathrm{kg}$ for patients older than 60 years, and protein: $1.2 \mathrm{~g} / \mathrm{kg}$ ) (7). Among patients undergoing hemodialysis, $6 \%$ to $8 \%$ suffer from severe malnutrition and 30\% - 65\% from mild malnutrition. The results of some studies have shown that one of the important causes of malnutrition is low dialysis adequacy in patients undergoing hemodialysis (5).

Evaluating the adequacy of dialysis in patients undergoing hemodialysis is important, and one of the signifi- 
cant goals of the health care team is high adequacy of dialysis (8). Dialysis adequacy affects appetite, intake of nutrients, and nutrition, while dialysis inadequacy is an important factor in patients' malnutrition and mortality (9). To determine the adequacy of dialysis, urea reduction ratio (URR) and kt/v (k: filter urea clearance used, t: dialysis duration, and v: volume of urea distribution or volume of water distribution are calculated. Determination of $\mathrm{kt} / \mathrm{v}$ is currently preferred to the URR (10). According to the Renal Physician Association (RPA) instruction in 1993, at least URR $>\% 65$ and $\mathrm{kt} / \mathrm{v}>1.2$ are considered for the adequacy of dialysis. The National Kidney Foundation (NKF)-Dialysis Outcomes Quality Initiative (DOQI) also identified this criterion in 1997 and changed the $\mathrm{kt} / \mathrm{v}$ value to 1.4 in 2006, and identified $\mathrm{kt} / \mathrm{v}>1.2$ as the acceptable minimum (11).

The nutritional status of hemodialysis patients affects their clinical conditions. The nutritional status evaluation has been an important therapeutic method for this group (12). Different methods are used to screen patients regarding malnutrition (13). The following nutrition evaluation methods are currently used for assessing the nutrition status of patients: anthropometric measurements, including patients' height and weight, triceps skinfold thickness (TSF), mid-arm circumference (MAC), body mass index (BMI), biochemical evaluations, including serum albumin, pre-albumin, hemoglobin, transferrin, total iron-binding capacity (TIBC), total lymphocyte count (TLC), C-reactive protein (CRP), nitrogen balance, and routine blood testing to measure sodium, potassium, calcium, phosphor, urea, keratin, etc., and nutrition questionnaires, such as Subjective Global Assessment (SGA), Malnutrition-Inflammation Score (MIS), Dialysis Malnutrition score (DMS) (14).

SGA is a common semi-quantitative method that determines malnutrition status in hemodialysis patients. It is a valid and reliable method that can predict mortality independently. This is a simple, non-invasive, and inexpensive method that evaluates patients' nutrition status mentally with no need for performing laboratory tests (15, 16). El-Sheikh and El-Ghazaly (17) claimed that dialysis dose positively correlates with serum albumin concentration, and increased albumin level can lead to lower mortality. Hemayati et al. (18) assessed 38 patients and showed that dialysis adequacy is linked to nutritional status; however, there is no significant relationship between dialysis adequacy and BMI and albumin levels.

\section{Objectives}

Due to the discrepancy between the results of studies and the limitations of studies with large sample size, this study was done to investigate the relationship between nutritional status based on SGA and dialysis adequacy and albumin levels in 300 patients undergoing hemodialysis.

\section{Methods}

\subsection{Study Setting}

This cross-sectional descriptive study was conducted in Tehran, Iran, in 2019. In this study, 300 qualified patients aged 18 to 75 were selected.

\subsection{Sample Size}

The sample size was calculated based on the following formula $\left(n=\frac{\frac{z^{2} p q}{d^{2}}}{1+\frac{1}{N}\left(\frac{z^{2} p q}{d^{2}}-1\right)}\right)$ and considering the statistical population of Iranian hemodialysis patients (19).

\subsection{Inclusion and Exclusion Criteria}

Inclusion criteria were the age of 18 to 75 years, performing hemodialysis at least twice a week, and starting hemodialysis at least three months before the study. Patients with a history of malignancy, hepatitis B, AIDS, or other acute infectious diseases, those unable to perform anthropometric measurements, and also those with episodes of hemodynamic instability following hemodialysis were excluded. Sampling was done by random clustering. First, hemodialysis centers in Tehran, Iran, were identified as clusters in the north, south, west, and east parts of the city. Eight centers were selected by the simple random method, and then all patients referring to the centers were studied. Informed consent was obtained from each participant.

\subsection{Data Collection}

Patients' weight was measured carefully with a calibrated Seca digital scale (with the accuracy of $100 \mathrm{~g}$ ). BMI was calculated based on the weight $(\mathrm{kg}) /$ height $\left(\mathrm{m}^{2}\right)$ formula, and participants were divided into underweight (BMI < 18.5), normal weight (BMI), overweight (BMI = 25 $30)$, and obese (BMI $=30)$ groups according to the World Health Organization category (20). After patients lied on the bed and before they were connected to the dialysis machine, $4 \mathrm{ml}$ of blood samples was taken from them to measure albumin, TIBC, BUN, and Cr. Next, demographic information was collected from patients, and the SGA form was completed. 
SGA form consists of two categories: medical history (including five sections: weight change, dietary intake, gastrointestinal symptoms, functional capacity, and disease and comorbidity data, such as physical injuries, burn, inflammatory diseases, and infection) and physical examination (including three sections: loss of subcutaneous fat, muscle wasting, and the presence of edema or ascites) (21). Normal parts are scored A, being influenced mildly or moderately will lead to obtaining B score, and being affected significantly will lead to gaining a C score. Finally, the total score will be as follows (Table 1) (16):

\begin{tabular}{ll}
\hline \multicolumn{2}{l}{ Table 1. The Subjective Global Assessment (SGA) Final Score } \\
\hline SGA final Score & Nutrition Status \\
\hline Most parts are scored A & well-nourished \\
Most parts are scored B & mild to moderately malnourished \\
Most parts are scored C & severely malnourished \\
\hline
\end{tabular}

Score A indicates normal nutrition, score B indicates moderate malnutrition, and score $\mathrm{C}$ represent severe malnutrition.

To confirm the reliability, the SGA form was repeated for 20 patients at a 30-day interval, and the agreement coefficient was 0.85 for two measurements. At the end of the dialysis session, the second sampling was performed, and patients were weighed again, and the results were recorded in data collection forms.

$\mathrm{Kt} / \mathrm{V}$ is a ratio without a unit of measurement and shows the volume of cleaned plasma divided by the volume of urea distribution. Calculations are as follows (9):

Daugirdas II: $\mathrm{kt} / \mathrm{v}=-\mathrm{Ln}(\mathrm{R}-0.008 \mathrm{t})+(4-3.5 \mathrm{R}) \mathrm{UF} . \mathrm{W}$

Where, Ln: natural logarithm, R: the ratio of BUN $(\mathrm{mg} / \mathrm{dL})$ after dialysis to BUN (mg/dl) before dialysis (BUN2/BUN1), T: duration of each dialysis session (hour), UF: the volume of ultra-filtration (liter), and W: weight after dialysis $(\mathrm{kg})$.

\subsection{Statistical Analysis}

Data were analyzed using SPSS 21 software. Based on the variables and distribution of data, parametric and nonparametric statistical tests, including descriptive statistics (mean, standard deviation, and absolute and relative frequency) and inferential statistics, such as paired $t$ test, Mann-Whitney test, chi-square test (to assess the homogeneity of the demographic characteristics of the intervention and control groups before the intervention), Wilcoxon test (to compare the mean changes in blood pressure among the patients before and after the intervention), and Mann-Whitney test (to compare the mean of blood pressure between the intervention and control groups) were used. A P-value of less than or equal to 0.05 was statistically significant.

\subsection{Ethical Consideration}

This study is part of a Master's thesis in critical care nursing that was approved by the Ethics Committee of Baqiyatallah University of Medical Sciences (ethical code: IR.BMSU.REC.1393.3). Ethical considerations of the Helsinki declaration and Committee on Publication Ethics (COPE) were observed by the researchers in this study.

\section{Results}

In this research, 300 patients (170 male (56.7\%) and 130 female $(43.3 \%)$ ) with an average age of $61.15+13.06$ years and an average dialysis duration of $27.76(+31.45)$ months were studied. The majority (87\%) of patients reported hemodialysis three times a week for four hours, and 13\% reported hemodialysis twice a week. Polysulfone filters were used for all patients.

The mean albumin concentration and TIBC were 3.55 ( \pm 0.43) and 268.18 ( \pm 65.24). The patients' mean dialysis adequacy was reported to be 1.07 (+ 0.27), which is lower than the acceptable minimum. Figure 1 shows the frequency of malnutrition based on the SGA index.

The chi-square test showed a significant statistical relationship between educational level and BMI of hemodialysis patients and their nutrition status, while this was not significant for gender (Table 2).

One-way analysis of variance (ANOVA) showed that the concentration of albumin and TIBC is significantly higher in hemodialysis patients with normal nutrition compared to those with mild to moderate or severe malnutrition (Table 3).

The results showed that dialysis adequacy was higher in patients with normal nutrition status; however, mean dialysis adequacy was lower than the acceptable minimum even in this group (Figure 2).

\section{Discussion}

The present study was done to investigate the relationship between nutritional status based on the SGA scale and dialysis adequacy and albumin levels in hemodialysis patients. Dialysis adequacy was associated with nutritional status and decreased with an increase in malnutrition.

The relative frequency of mild to moderate and severe malnutrition based on SGA in this study was 57.3\%, which 


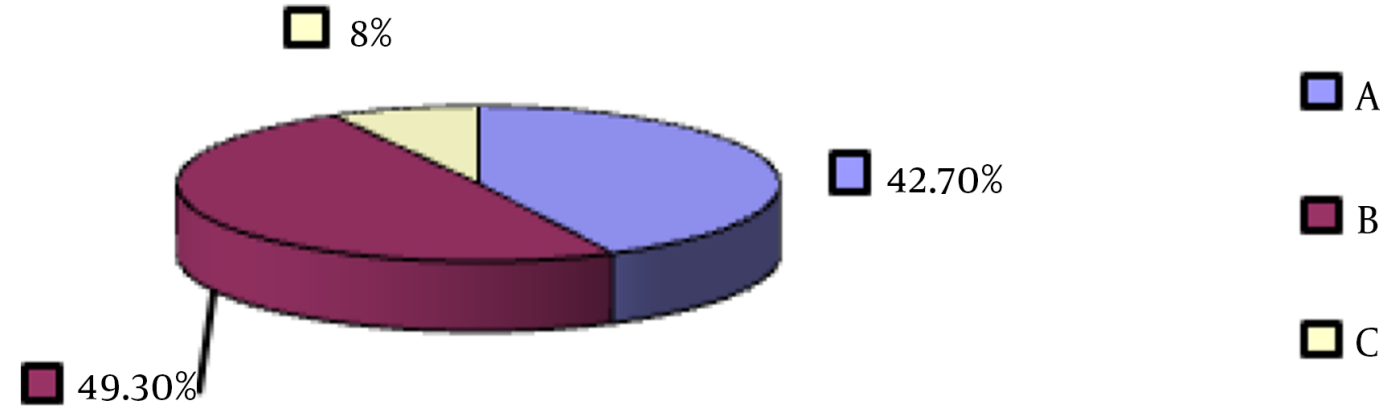

Figure 1. The nutritional status based on the Subjective Global Assessment (SGA)

Table 2. The Relationship Between Gender, Education, and Body Mass Index (BMI) of Hemodialysis Patients and Their Nutrition Status Based on the Subjective Global Assessment (SGA) Index ${ }^{\mathrm{a}}$

\begin{tabular}{|c|c|c|c|c|c|}
\hline \multirow{2}{*}{ Parameter } & \multicolumn{3}{|c|}{ Frequency (Relative Frequency) Based on SGA } & \multirow{2}{*}{ Total } & \multirow{2}{*}{ Chi-Square Test } \\
\hline & $\mathbf{A}$ & B & C & & \\
\hline Gender & & & & & $\chi^{2}=2.32 ; \mathrm{df}=2 ;$ P-value $=0.31$ \\
\hline Male & $78(29.5)$ & $81(47.6)$ & $11(6.5)$ & 170 & \\
\hline Female & $50(38.5)$ & $67(51.5)$ & $13(10)$ & 130 & \\
\hline Education & & & & & $\chi^{2}=34.7 ; \mathrm{df}=4 ;$ P-value $<0.001^{*}$ \\
\hline Primary and lower & $33(29.5)$ & $67(59.8)$ & $12(10.7)$ & 112 & \\
\hline Diploma & $39(36.1)$ & $59(54.6)$ & $10(9.3)$ & 108 & \\
\hline University & $56(70)$ & $22(27.5)$ & $2(2.5)$ & 80 & \\
\hline BMI, $\mathrm{kg} / \mathrm{m}^{2}$ & & & & & $\chi^{2}=13.7 ; \mathrm{df}=6 ;$ P-value $=0.03^{*}$ \\
\hline Under weight & $4(20)$ & $11(55)$ & $5(25)$ & 20 & \\
\hline Normal & $80(48.2)$ & $75(45.2)$ & $11(6.6)$ & 166 & \\
\hline Over weight & $29(39.7)$ & $38(52.1)$ & $6(8.2)$ & 73 & \\
\hline Obesity & $15(36.6)$ & $24(58.5)$ & $2(4.9)$ & 41 & \\
\hline Total & $128(42.7)$ & $148(49.3)$ & $24(8)$ & 300 & \\
\hline
\end{tabular}

$\mathrm{a}^{*}$, statistical significance, score A is normal nutrition status, score B is moderate malnutrition, score C is severe malnutrition.

agrees with previous studies in Iran and other countries $(20,22,23)$. Todd et al. (24) reported moderate malnutrition in Australian hemodialysis patients, and Mazairac et al. (25), in a multicenter study, reported a malnutrition prevalence of $23 \%$ in a large cohort of 560 patients. According to different studies, insufficient intake of daily energy and protein, limitation in receiving special food groups, lack of appetite, and loss of water-soluble nutrients during hemodialysis, and also unnatural metabolism of nutrients can lead to unfavorable nutritional conditions (26-28).

A cohort study showed that gender has a significant relationship with the relative frequency of malnutrition based on the SGA index (6). This finding is in line with the present study and is in contrast to the results of Ashabi et al. (23).

In the present study, the relative frequency of malnutrition in hemodialysis patients showed no significant relationship with age; however, in a study Ashabi et al. (23), the relative frequency of malnutrition in patients younger than 60 years was $75 \%$, and it was $45 \%$ in patients older than 60 years.

Different studies have shown that the relative frequency of malnutrition in hemodialysis patients is higher in patients with longer dialysis duration compared to those with shorter periods $(29,30)$. This contradicts the present study, which can be due to the number of samples, 
Afaghi E et al.

\begin{tabular}{|c|c|c|c|c|}
\hline Parameter & Nutritional Status & Mean \pm SD & Confidence Interval (95\%) & ANOVA \\
\hline \multirow{4}{*}{ Age, $y$} & A & $60.69 \pm 14.24$ & $58.20-63.18$ & \multirow{4}{*}{$F=0.260 ; D f=297 ; P$-value $=0.77$} \\
\hline & B & $61.70 \pm 11.92$ & $59.76-63.63$ & \\
\hline & $\mathrm{C}$ & $60.29 \pm 13.64$ & $54.53-66.05$ & \\
\hline & Total & $61.15 \pm 13.06$ & $59.76-62.64$ & \\
\hline \multirow{4}{*}{ hemodialysis duration, mon } & A & $27.30 \pm 34.99$ & $21.18-33.42$ & \multirow{4}{*}{$\mathrm{F}=1.01 ; \mathrm{Df}=297 ; \mathrm{P}$-value $=0.36$} \\
\hline & B & $26.74 \pm 26.49$ & $22.43-31.04$ & \\
\hline & $\mathrm{C}$ & $36.5 \pm 38.99$ & $20.03-52.97$ & \\
\hline & Total & $27.76 \pm 31.45$ & $24.18-31.33$ & \\
\hline \multirow{4}{*}{ Albumin, mg/dL } & A & $3.78 \pm 0.35$ & $3.72-3.84$ & \multirow{4}{*}{$\mathrm{F}=78.64 ; \mathrm{Df}=297 ; \mathrm{P}$-value $<0.001$} \\
\hline & B & $3.46 \pm 0.33$ & $3.40-3.51$ & \\
\hline & $\mathrm{C}$ & $2.85 \pm 0.44$ & $2.66-3.04$ & \\
\hline & Total & $3.55 \pm 0.43$ & $3.50-3.60$ & \\
\hline \multirow{4}{*}{ TIBC, mg/dL } & A & $279.98 \pm 53.68$ & $270.59-289.37$ & \multirow{4}{*}{$\mathrm{F}=11.25 ; \mathrm{Df}=297 ; \mathrm{P}$-value $<0.001$} \\
\hline & B & $266.83 \pm 70.54$ & $255.37-278.29$ & \\
\hline & $\mathrm{C}$ & $213.58 \pm 60.96$ & $187.84-239.33$ & \\
\hline & Total & $268.18 \pm 65.24$ & $260.77-275.60$ & \\
\hline \multirow{4}{*}{ Dialysis adequacy } & A & $1.17 \pm 0.21$ & $1.13-1.21$ & \multirow{4}{*}{$\mathrm{F}=43.72 ; \mathrm{Df}=297 ; \mathrm{P}$-value $<0.001$} \\
\hline & $\mathrm{B}$ & $1.03 \pm 0.23$ & $1-1.07$ & \\
\hline & $\mathrm{C}$ & $0.69 \pm 0.37$ & $0.53-0.85$ & \\
\hline & Total & $1.07 \pm 0.27$ & $1.03-1.1$ & \\
\hline
\end{tabular}

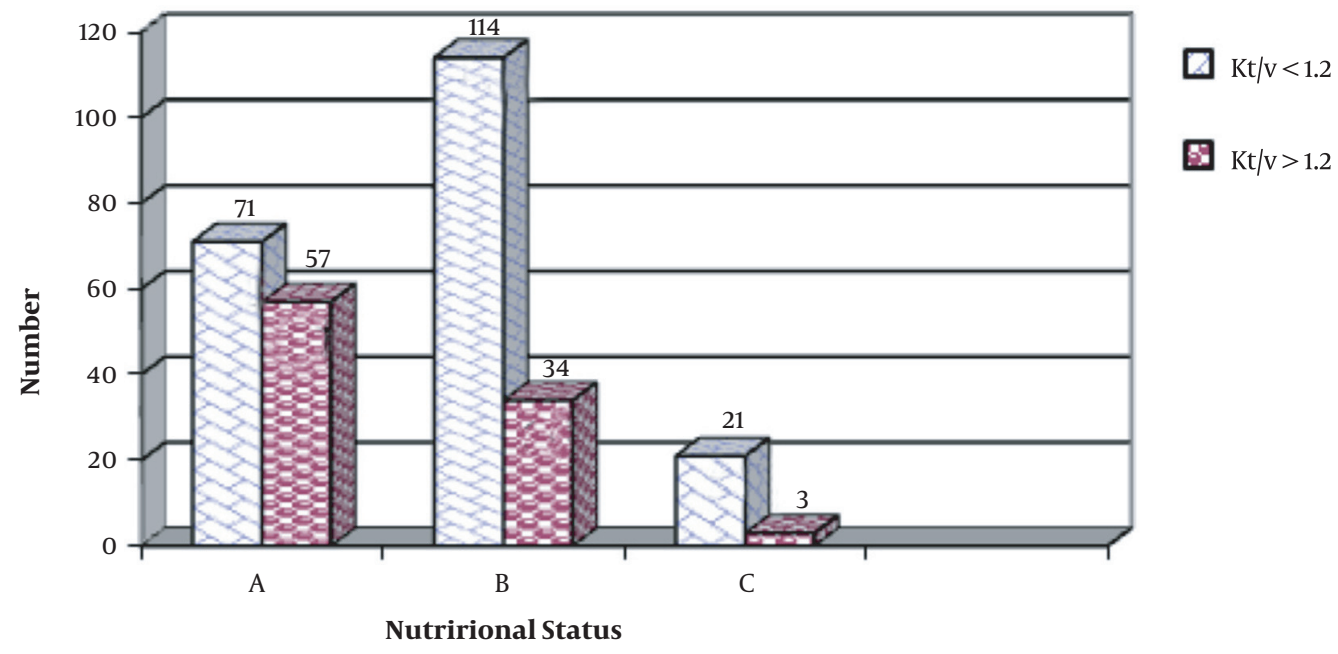

Figure 2. The relationship between dialysis adequacy and nutrition status based on the Subjective Global Assessment (SGA) index

sampling method, geographical location, etc.

We found that higher education leads to better nutrition, which keeps the body weight in a healthy range and is associated with better BMI. de Mutsert et al. (31) declared that there is a significant relationship between BMI and nutritional status based on the SGA index. 
One of the important mortality predictors in patients suffering from chronic renal failure is a reduction in albumin serum concentration (hypo-albumin). The risk of mortality is seven times more for each $1-\mathrm{g} / \mathrm{dL}$ decrease in albumin serum concentration. Albumin level is not the only indicator of the nutritional status and is decreased by inflammations; however, it is appropriate in identifying people at risk of malnutrition (31-33). The findings of this research showed that hypo-albumin is statistically related to malnutrition, which is consistent with the results of Cohort studies by Chan et al. (6) and de Mutsert et al. (31).

TIBC is also an indicator of nutritional status and is used in nutrition assessment scales, such as MIS (34). Some quantitative studies have been done on the relationship between TIBC and malnutrition status based on the SGA index. The present study showed that similar to albumin, TIBC has also a significant relationship with nutritional status and it is lower in hemodialysis patients with moderate and severe malnutrition.

The present study showed that the adequacy of dialysis in patients was lower than the standard value, which agrees with many studies $(35,36)$. Urea uptake in a dialysis session is an important factor for the adequacy of dialysis and dialysis adequacy is not related to plasma urea alone. Venous stenosis, arterial-venous fistula, failure to follow regular dialysis programs by patients, hemodynamic instability, cardiovascular diseases, and infections are among the proposed reasons for dialysis inadequacy $(37,38)$. According to the present study, malnutrition can be also considered as a factor leading to dialysis inadequacy, and there is a direct relationship between them.

There are several reasons for the difference in the prevalence of malnutrition and its associated factors, such as, such as the adequacy of dialysis in different studies can be due to differences in methods of assessing malnutrition, different age groups, duration of illness, and underlying diseases, drug use, and socioeconomic factors, including the patient's level of education and knowledge about the disease, family support, the level of access to food, eating habits, and culture in each region, which can affect the nutritional status.

This research was a multicenter study in which participants from different backgrounds can be included, which is one of the strengths of this study. Decrease in dialysis time period due to patient intolerance, stopping or slowing down dialysis due to complications during dialysis, such as hypotension, muscle cramps, and angina, and finally filter $\mathrm{k}$ parameter less than what the company claimed, were among the limitations of the study.

\subsection{Conclusions}

The results showed a significant statistical relationship between nutritional status and education, BMI, albumin, TIBC, and dialysis adequacy. Therefore, training workshops for educating patients about proper hemodialysis, keeping weight at normal range, the use of nutritional supplements along with routine diet to receive nutrients, monthly check of dialysis adequacy, investigation of patients' nutritional status through different methods, and the presence of a diet specialist are necessary for hemodialysis wards. We hope this study prepares backgrounds for future interventional studies.

\section{Acknowledgments}

The author thanks patients, physicians, nurses, and other personnel of selected dialysis centers in Tehran, lab officials, and experts who assisted in performing the research.

\section{Footnotes}

Authors' Contribution: EA performed data collection and drafting of the manuscript. AT was responsible for the study conception and design. SAS performed preliminary analysis and made critical revisions for important intellectual content. AE was responsible for the study design and data analysis. All authors reviewed the manuscript.

Conflict of Interests: The authors declared no conflict of interests.

Ethical Approval: This study is part of a Master's thesis in critical care nursing that was approved by the Ethics Committee of Baqiyatallh University of Medical Sciences (ethical code: IR.BMSU.REC.1393.3). Ethical considerations of the Helsinki declaration and Committee on Publication Ethics (COPE) were observed by the researchers in this study.

Funding/Support: This article did not receive any financial support from institutions.

Informed Consent: Informed consent was obtained from each participant.

\section{References}

1. Kalantar-Zadeh K. Protein-Energy Wasting. Nutrition in Kidney Disease. Springer; 2014. p. 219-30. doi:10.1007/978-1-62703-685-6_13.

2. Hernandez Morante JJ, Sanchez-Villazala A, Cutillas RC, Fuentes MC. Effectiveness of a nutrition education program for the prevention and treatment of malnutrition in end-stage renal disease. J Ren Nutr. 2014;24(1):42-9. doi: 10.1053/j.jrn.2013.07.004. [PubMed: 24216257]. 
3. Malgorzewicz S, Aleksandrowicz-Wrona E, Owczarzak A, DebskaSlizien A, Rutkowski B, Lysiak-Szydlowska W. Adipokines and nutritional status for patients on maintenance hemodialysis. J Ren Nutr. 2010;20(5):303-8. doi: 10.1053/j.jrn.2009.10.005. [PubMed: 20071195].

4. Kutsal DA, Kursat S, Inci A, Ulman C, OzanUtuk I. The relationship between malnutrition subgroups and volume parameters in pre-dialysis patients. Saudi J Kidney Dis Transpl. 2016;27(1):81-7. doi: 10.4103/1319-2442.174082. [PubMed: 26787571].

5. Heng AE, Cano NJM. Nutritional problems in adult patients with stage 5 chronic kidney disease on dialysis (both haemodialysis and peritoneal dialysis). Clin Kidney J. 2009;3(2):109-17. doi: 10.1093/ndtplus/sfp147.

6. Chan M, Kelly J, Batterham M, Tapsell L. Malnutrition (subjective global assessment) scores and serum albumin levels, but not body mass index values, at initiation of dialysis are independent predictors of mortality: a 10-year clinical cohort study. J Ren Nutr. 2012;22(6):54757. doi: 10.1053/j.jrn.2011.11.002. [PubMed: 22406122].

7. Mohamed S, Abdullah AL. Assessment of Dietary Management of Patient during Dialysis. Int J Sci Res. 2014;3(1):66-70.

8. Dehvan F, Monjazebi F, Erfani Khanghahi M, Mohammadi H, Ghanei Gheshlagh R, Kurdi A. Adequacy of Dialysis in Iranian Patients Undergoing Hemodialysis: A Systematic Review and Meta-Analysis. NephroUrol Mon. 2018;10(5). doi: 10.5812/numonthly.82235.

9. Afaghi E, Tayebi A, Ebadi A, Sobhani V, Einollahi B, Tayebi M. The Effect of BCAA and ISO-WHEY Oral Nutritional Supplements on Dialysis Adequacy. Nephrourol Mon. 2016;8(6). e34993. doi: 10.5812/numonthly.34993. [PubMed: 27896236]. [PubMed Central: PMC5120366].

10. Ghorbane Moghaddam Z, Sharifi S, Raeese A, Yazdankhah Fard M, Mirzaee K, Bahraine M. Investigation of hemodialysis adequacy in patients undergoing hemodialysis in the Shohada Hospital in Bushehr. ISMJ. 2016;18(6):1236-44.

11. Esmaili H, Majlessi F, Montazeri A, Sadeghi R, Nedjat S, Zeinali J. Dialysis adequacy and necessity of implement health education models to its promotion in Iran. Int J Res Health Sci. 2018;5(10):116-21.

12. Tsai MT, Liu HC, Huang TP. The impact of malnutritional status on survival in elderly hemodialysis patients. J Chin Med Assoc. 2016;79(6):309-13. doi:10.1016/j.jcma.2016.01.015. [PubMed:27071984].

13. Taghdir M, Ashourpour M, Ghandchi Z, Pourghaderi M, Sepandi M, ALAVI NA. Assessment of energy and protein intake and some of the related factors in hemodialysis patients referred to Imam Khomeini hospital. Iran J Endocrin Metab. 2012;13(6):690-6.

14. Roy L, Shetty M, Urooj A. Screening of Malnutrition Using Clinical, Dietary and Anthropometric Variables in an Indian Hemodialysis Population. JMED Res. 2015:1-14. doi: 10.5171/2015.847823.

15. Spatola L, Finazzi S, Calvetta A, Reggiani F, Morenghi E, Santostasi S, et al. Subjective Global Assessment-Dialysis Malnutrition Score and cardiovascular risk in hemodialysis patients: an observational cohort study. J Nephrol. 2018;31(5):757-65. doi: 10.1007/s40620-018-05053. [PubMed: 29936648].

16. Prasad N, Sinha A. Subjective Global Assessment (SGA) of Malnutrition. In: Preedy VR, Patel VB, editors. Handbook of Famine, Starvation, and Nutrient Deprivation. 2019. p. 643-63. doi: 10.1007/978-3-319-553870_116.

17. El-Sheikh M, El-Ghazaly G. Assessment of hemodialysis adequacy in patients with chronic kidney disease in the hemodialysis unit at Tanta University Hospital in Egypt. Indian J Nephrol. 2016;26(6):398404. doi:10.4103/0971-4065.168141. [PubMed: 27942169]. [PubMed Central: PMC5131376].

18. Hemayati R, Lesanpezeshki M, Seifi S. Association of dialysis adequacy with nutritional and inflammatory status in patients with chronic kidney failure. Saudi J Kidney Dis Transpl. 2015;26(6):1154-60. doi: 10.4103/1319-2442.168593. [PubMed: 26586053].

19. Aghighi M, Heidary Rouchi A, Zamyadi M, Mahdavi-Mazdeh M, Ra- jolani H, Ahrabi S, et al. Dialysis in Iran. Iran J Kidney Dis. 2008;2(1):11-5. [PubMed: 19367003].

20. Espahbodi F, Khoddad T, Esmaeili L. Evaluation of malnutrition and its association with biochemical parameters in patients with end stage renal disease undergoing hemodialysis using subjective global assessment. Nephrourol Mon. 2014;6(3). e16385. doi: 10.5812/numonthly.16385. [PubMed: 25032136]. [PubMed Central: PMC4090668].

21. Kwon YE, Kee YK, Yoon CY, Han IM, Han SG, Park KS, et al. Change of Nutritional Status Assessed Using Subjective Global Assessment Is Associated With All-Cause Mortality in Incident Dialysis Patients. Medicine (Baltimore). 2016;95(7). e2714. doi: 10.1097/MD.0000000000002714. [PubMed: 26886609]. [PubMed Central: PMC4998609].

22. Janardhan V, Soundararajan P, Rani NV, Kannan G, Thennarasu P, Chacko RA, et al. Prediction of Malnutrition Using Modified Subjective Global Assessment-dialysis Malnutrition Score in Patients on Hemodialysis. Indian J Pharm Sci. 2011;73(1):38-45. doi: 10.4103/0250474X.89755. [PubMed: 22131620]. [PubMed Central: PMC3224408].

23. Ashabi A, Nozari B, Tabibi H, Mahdavi-Mazdeh M, Hedayati MAHDI, Rad AH. Prevalence of protein-energy malnutrition and its various types in hemodialysis patients in Tehran, 2008. Iran J Nutr Sci Food Technol. 2010;5(1):17-28.

24. Todd A, Carroll R, Gallagher M, Meade A. Nutritional status of haemodialysis patients: comparison of Australian cohorts of Aboriginal and European descent. Nephrology (Carlton). 2013;18(12):790-7. doi: 10.1111/nep.12165. [PubMed: 24118237].

25. Mazairac AH, de Wit GA, Grooteman MP, Penne EL, van der Weerd NC, van den Dorpel MA, et al. A composite score of protein-energy nutritional status predicts mortality in haemodialysis patients no better than its individual components. Nephrol Dial Transplant. 2011;26(6):1962-7. doi:10.1093/ndt/gfq643. [PubMed: 20947533].

26. Gencer F, Yildiran H, Erten Y. Association of Malnutrition Inflammation Score With Anthropometric Parameters, Depression, and Quality of Life in Hemodialysis Patients. J Am Coll Nutr. 2019;38(5):457-62. doi: 10.1080/07315724.2018.1550371. [PubMed:30589395].

27. Wulandari H, Prasanto H; Susetyowati. Comparison between brief food frequency questionnaire and food record to assess the energy and protein intake of hemodialysis patients at Dr. Sardjito Hospital in Indonesia. Saudi J Kidney Dis Transpl. 2018;29(1):145-52. doi: 10.4103/1319-2442.225196. [PubMed: 29456221].

28. As' habi A, Tabibi H, Hedayati M, Mahdavi-Mazdeh M, Nozari B. Association of energy-protein malnutrition with risk factors of cardiovascular diseases in hemodialysis patients. Iran J Nutr Sci Food Technol. 2011;6(2):0.

29. Mekki K, Remaoun M, Belleville J, Bouchenak M. Hemodialysis duration impairs food intake and nutritional parameters in chronic kidney disease patients. Int Urol Nephrol. 2012;44(1):237-44. doi: 10.1007/s11255-010-9875-8. [PubMed: 21104434].

30. Andrew NH, Engel B, Hart K, Passey C, Beaden S. Micronutrient intake in haemodialysis patients. J Hum Nutr Dietetics. 2008;21(4):375-6.

31. de Mutsert R, Grootendorst DC, Boeschoten EW, Brandts H, van Manen JG, Krediet RT, et al. Subjective global assessment of nutritional status is strongly associated with mortality in chronic dialysis patients. Am J Clin Nutr. 2009;89(3):787-93. doi:10.3945/ajcn.2008.26970. [PubMed: 19144733].

32. Eriguchi R, Obi Y, Streja E, Tortorici AR, Rhee CM, Soohoo M, et al. Longitudinal Associations among Renal Urea Clearance-Corrected Normalized Protein Catabolic Rate, Serum Albumin, and Mortality in Patients on Hemodialysis. Clin J Am Soc Nephrol. 2017;12(7):110917. doi: 10.2215/CJN.13141216. [PubMed: 28490436]. [PubMed Central: PMC5498364].

33. Ma L, Zhao S. Risk factors for mortality in patients undergoing hemodialysis: A systematic review and meta-analysis. Int J Cardiol. 
2017;238:151-8. doi: 10.1016/j.ijcard.2017.02.095. [PubMed: 28341375].

34. He T, An X, Mao HP, Wei X, Chen JH, Guo N, et al. Malnutritioninflammation score predicts long-term mortality in Chinese PD patients. Clin Nephrol. 2013;79(6):477-83. doi: 10.5414/CN107659. [PubMed: 23391316].

35. Nemati E, Khosravi A, Einollahi B, Meshkati M, Taghipour M, Abbaszadeh $\mathrm{S}$. The relationship between dialysis adequacy and serum uric acid in dialysis patients; a cross-sectional multi-center study in Iranian hemodialysis centers. J Renal Inj Prev. 2017;6(2):142-7. doi: 10.15171/jrip.2017.28. [PubMed: 28497092]. [PubMed Central: PMC5423283].

36. Somji SS, Ruggajo P, Moledina S. Adequacy of Hemodialysis and Its
Associated Factors among Patients Undergoing Chronic Hemodialysis in Dar es Salaam, Tanzania. Int J Nephrol. 2020;2020:9863065. doi: 10.1155/2020/9863065. [PubMed: 32095287]. [PubMed Central: PMC7035558].

37. Barzegar H, Moosazadeh M, Jafari H, Esmaeili R. Evaluation of dialysis adequacy in hemodialysis patients: A systematic review. Urol J. 2016;13(4):2744-9. [PubMed: 27576879].

38. Rezaiee O, Shahgholian N, Shahidi S. Assessment of hemodialysis adequacy and its relationship with individual and personal factors. Iran J Nurs Midwifery Res. 2016;21(6):577-82. doi: 10.4103/1735-9066.197673. [PubMed: 28194196]. [PubMed Central: PMC5301063]. 